\section{Spare the rods and spoil the retina: revisited}

\begin{abstract}
Visual function improves with oxygen inhalation in people with diabetes even in the absence of visible retinopathy. Rods consume the most oxygen in the retina due to the high metabolic activity required to maintain the dark current. Therefore, Arden hypothesized that in diabetes where oxygen supply may also be affected due to the changes in retinal vasculature, prevention of dark adaptation may be a viable option to prevent or decrease the rate of progression of diabetic retinopathy. Animal experiments have proven that the absence of rods decreases the development of retinal neovascularisation. The same principle applies to panretinal photocoagulation, an established treatment for proliferative diabetic retinopathy. Recently, a few clinical studies have also shown that preventing dark adaptation by suppressing rods with $500-\mathrm{nm}$ light source at night decreases the rate of progression of early diabetic retinopathy and maculopathy in the short-term. We await the results of a large two-year multi-centre trial (CLEOPATRA trial) to evaluate the long-term effects of decreasing dark adaptation by applying a $500-\mathrm{nm}$ light source as a mask over eyes with non-central diabetic macular oedema.
\end{abstract}

Eye (2016) 30, 189-192; doi:10.1038/eye.2015.254; published online 11 December 2015

Diabetic retinopathy (DR) is a degenerative neurovascular complication of diabetes mellitus. ${ }^{1}$ Numerous aspects of its pathogenesis have been explored, in the past, and various factors/pathways have been identified to be involved but the focus has been on microvascular changes in the inner retina. ${ }^{2}$ In 1998, Arden et al hypothesized that the rod system in the outer retina may be a major contributor to the development and progression
S Sivaprasad and G Arden

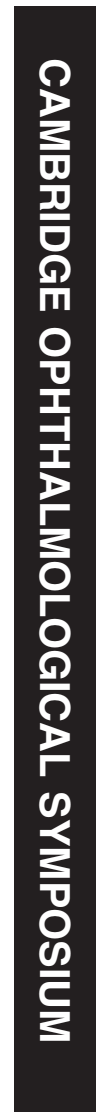

Are rods involved in the development and progression of DR?

Kern and Engermann compared microvascular changes in the brain and retina in 10 diabetic dogs. ${ }^{7}$ They observed that microvascular changes evident in the retina were not seen in the brain and concluded that there is a local factor in the eye that causes these microvascular changes. Arden then observed that people with diabetes and retinitis pigmentosa do not develop DR and hypothesized that rods may be the local factors that contribute to the pathogenesis of microvascular changes. ${ }^{3}$ This finding has been corroborated in animal experiments. De Gooyer et al showed that rhodopsin knockout mice (retinitis pigmentosa model) superimposed with diabetes showed significantly less severity of microvascular changes and decrease gene expression of VEGF than wild-type diabetic mice. ${ }^{8}$

What happens in dark adaptation

Light captured by visual pigments in rod and cone cells of the retina triggers phototransduction. In the rods, the photoexcitation of rhodopsin activates
NIHR Moorfields Biomedical Research Centre, London, UK

Correspondence:

S Sivaprasad, Medical Retina, NIHR Moorfields Biomedical Research Centre, 162 City Road, EC1V 2PD London, UK Tel: +44 2075662039; Fax: +44 2075662972. E-mail: senswathi@aol.com

Received: 2 November 2015 Accepted: 10 November 2015 Published online: 11 December 2015 
transducin, hydrolyzing cGMP and in turn closure of the cGMP-gated cation channel and the cell is hyperpolarized. In the dark, a steady current flows into the open channels, carried mainly by sodium ions, constituting a 'dark current' that depolarizes the photoreceptor cell. In the inner segment, there are pumps that expel the sodium and water from the rod. This process requires a great deal of energy. Depolarized rods in dark also release large amounts of glutamate, their neurotransmitter, which also increases energy utilization and oxygen consumption. Therefore, the partial pressure of oxygen $\left[\mathrm{PO}_{2}\right]$ at the level of photoreceptors reduces to near zero resulting in a relative hypoxia in this layer compared with other retinal layers. ${ }^{9-12}$

\section{Oxygen consumption by rod photoreceptors}

The outer retina consists predominantly of photoreceptors and is avascular. It derives most of its oxygen supply from the choroidal circulation that has high $\mathrm{PO}_{2}$, whereas $15 \%$ supply is from the retinal circulation..$^{9-12}$ The $\mathrm{O}_{2}$ utilization in the outer retina occurs in the photoreceptor inner segments and the $\mathrm{PO}_{2}$ in the inner segments approach zero in the dark in many animals due to the extraordinarily high oxygen consumption by the rods. ${ }^{11-17}$ Okawa et al estimated that the rod-specific metabolic rate is $13 \mu \mathrm{mol}$ ATP per minute per gram in darkness. In bright light, retinal $\mathrm{O}_{2}$ consumption decreases by $40-60 \%$ mostly due to the drop in ATP consumption by the rods. ${ }^{18}$ In animal experiments, the $\mathrm{PO}_{2}$ rises suddenly and briefly when the retina is stimulated by a flash of light providing evidence of the effect of dark current on oxygen consumption. Under light-adapted conditions, the influx of $\mathrm{Na}+$ decreases, which decreases the metabolic demand for $\mathrm{Na}+/ \mathrm{K}+$ pumping, whereas the turnover of cGMP in the outer segment increases oxygen utilization. The net oxygen consumption is the summation of the two opposite effects of light on $\mathrm{Na}+/ \mathrm{K}+$ pumping and cGMP turnover. $9,18,19$ The relative values should depend on rates of enzymatic processes, numbers of channels and pumps, and the geometry of the photoreceptors, so it would lead to a difference in the net effect of light on $\mathrm{O}_{2}$ consumption in different species. ${ }^{17}$

Therefore, in diabetes where the availability of oxygen is already compromised, the normal dark adaptation process that causes an outer retinal increase in oxygen consumption may be sufficient to initiate the hypoxic environment that triggers microvascular changes.

One may argue that the choroidal circulation is not compromised in diabetes so the supply demand of oxygen in the retina is not compromised. There is sufficient evidence to suggest that choroidal blood flow is reduced earlier than retinal blood flow in diabetic mice ${ }^{20}$ and that choroidal angiopathy is an early feature in human diabetic eyes. ${ }^{21}$ Choroidal blood flow is also not regulated metabolically, so systemic hypoxia leads to decreases in choroidal $\mathrm{PO}_{2}$ and photoreceptor $\mathrm{O}_{2}$ consumption explaining why systemic hypoxia as seen in sleep apnoea has detrimental effects on DR. In fact, more than five episodes of decrease arterial oxygen saturation to $<90 \%$ saturated per night is enough to significantly exacerbate the retinopathy.

\section{Evidence that oxygen supplementation improves visual function changes and retinopathy in diabetes}

Visual loss in people with diabetes begins with an insidious reduction in night vision or the ability to see details in low light conditions, ${ }^{22}$ suggesting that the rod function is the first to be affected. There is also evidence that contrast sensitivity is reduced in eyes before clinical evidence of diabetic microvascular changes. Inspiration of gas with an elevated fraction of $\mathrm{O}_{2}$ improves retinal and visual function during diabetes implying that the diabetic retina is hypoxic. ${ }^{23-25}$ Another example is panretinal photocoagulation that causes new vessel regression by reducing the hypoxia induced VEGF drive. The treatment reduces the hypoxic state by decreasing the metabolic demand of the photoreceptors and improving oxygenation of the retina and thereby reducing VEGF stimulation ${ }^{26}$. Similarly, oxygen therapy improves non-central macular edema in the short term. ${ }^{27}$ Patients with mild reduction in arterial hemoglobin saturation due to sleep apnoea have more severe retinopathy than those whose airways do no obstruct at night. Positive pressure ventilation in such patients also reduces the rate of progression of DR. ${ }^{28-32}$

\section{Does illuminating the retina reduce the risk of progression of retinopathy?}

Trans-lid retinal illumination of one eye in 12 patients with DR during sleep over 3 months resulted in a reduction of tritan thresholds and a reduction in the number hemorrhages and microaneurysms on fundus photographs compared with the contralateral eyes. ${ }^{33}$ Furthermore, another clinical trial on 40 patients with mild non-proliferative DR and early, untreated non-sightthreatening diabetic macular oedema (DMO) who slept for 6 months wearing masks that illuminated the eyelid of one closed eye with 505-nm light over 6 months also showed regression of the macular oedema and improved visual function. ${ }^{34}$ The longer-term effects of this treatment option on non-central DMO is now being evaluated in a phase III randomised controlled single-masked multicentre clinical trial over 2 years (CLEOPATRA trial). ${ }^{35}$ 
Can any other mechanism explain the role of rods in diabetic retinopathy?

Oxidative stress, that is, the production of high-energy radicals by altered action of mitochondria, is certainly increased in diabetic retina. The photoreceptors produce a very large majority of such radicals level and oxidative stress increases in dark-adapted eyes again pointing out that the dark current of the rods contribute to the development of DR. ${ }^{36}$

\section{Does increase illumination harm the rods?}

It is unlikely that this modest increase in $\mathrm{PO}_{2}$ is harmful to the cell even when the illumination is maintained for long periods. ${ }^{37}$ The value of $\mathrm{PO}_{2}(20 \mathrm{mmHg})$ found in the vicinity of the rod mitochondria in bright light is similar to the value measured by Linsenmeier and Braun in both darkness and light in the inner retina of the cat. ${ }^{10}$ As the cells of the inner retina are exposed to an oxygen tension of about $20 \mathrm{~mm} \mathrm{Hg}$ continuously during the life of the organism and remain unaffected, it is unlikely that the increase in oxygen tension caused by exposing the rods to steady light would be deleterious. This would argue against the notion that continuous stimulation of the rods by real or equivalent light can produce deleteriously elevated $\mathrm{O}_{2}$ in the outer retina and lead to cell death.

\section{Are the cones involved in 507-nm illumination?}

The oxygen consumption in the cones does not decrease as significantly in light as is the case for rods despite the fact that rods and cones have similar ATP expenditure and dark current amplitude because, in bright light, a cone will use much more ATP than a rod and the ATP required by cones in bright light is approximately as large as required in darkness. Furthermore, rods greatly outnumber cones (95-5\%), so that exposure to bright steady light produces a net decrease in retinal ATP and $\mathrm{O}_{2}$ utilization. ${ }^{8,9,13}$

One may question is the role of the mitochondria in the cones. The mitochondrial density in foveal cone inner segments is $\sim 60 \%$ higher than that in perifoveal rods and the inner segments are longer in the fovea. ${ }^{38}$ The mitochondrion is the site of sequestration of oxygen in oxidative phosphorylation pathways, which produce high-energy phosphorylated nucleotides, especially ATP.

Mitochondrial repair has recently become of considerable interest because this process seems to occur when deep red light $(670 \mathrm{~nm})$ is used to irradiate the retina (and other tissues). This light is absorbed to an insignificant amount by the rods and even the cones, and there are no pigments with an absorption spectrum that corresponds to the observations. However, the peak of the difference spectrum between various energy levels of cytochrome oxidase is near this wavelength, strongly suggesting that the efficiency of the mitochondrion can be affected by such radiation. Kern et al have demonstrated that $670-\mathrm{nm}$ light exposure for a mere $83 \mathrm{~s}$ results in resolution of non-central DMO. The details of how this mechanism operates are unclear. ${ }^{36}$

\section{Melanopsin and illumination of the retina}

Apart from the rods and cones, there are melanopsinexpressing intrinsically photoreceptive retinal ganglion cells (ipRGCs). The question arises whether these cells contribute to the effect of 507-nm light on the retina. ipRGCs comprise only a small fraction of $<5 \%$ of the total ganglion cell population that function in circadian entrainment and the pupillary reflex. First, the amount of 507-nm light required is so low that ipGRCs are unlikely to be active. Although we cannot be certain, the maximum spectral sensitivity of ipRGCs is at $\sim 480$ nm. ${ }^{39}$ The ipRGCs also lack specialized photopigmentconcentrating organelles (such as rod/cone outer segments) to maximize the probability of photon capture. As a result, the probability of absorbing a photon is $>1$ million times lower than in the rods or cones for a given area of photostimulation.

\section{Conclusion}

Over the past 20 years, the important role played by photoreceptors in the development of retinal disease has become apparent, and the mechamisms whereby this occurs are now better understood. The advances in knowledge suggest that noninvasive treatment by light may be an important adjunct therapy in DR.

\section{Conflict of interest}

SS is the Chief Investigator of the CLEOPATRA study. The other author declares no conflict of interest.

\section{References}

1 Stem MS, Gardner TW. Neurodegeneration in the pathogenesis of diabetic retinopathy: molecular mechanisms and therapeutic implications. Curr Med Chem 2013; 20(26): 3241-3250.

2 Stitt AW, Curtis TM, Chen M, Medina RJ, McKay GJ, Jenkins A et al. The progress in understanding and treatment of diabetic retinopathy. Prog Retin Eye Res 2015; e-pub ahead of print 18 August 2015; doi:10.1016/j.preteyeres.2015.08.001.

3 Arden GB, Wolf JE, Tsang Y. Does dark adaptation exacerbate diabetic retinopathy? Evidence and a linking hypothesis. Vision Res 1998; 38: 1723-1729. 
4 Arden GB. The absence of diabetic retinopathy in patients with retinitis pigmentosa: implications for pathophysiology and possible treatment. Br J Ophthalmol 2001; 85(3): 366-370.

5 Arden GB, Sidman RL, Arap W, Schlingemann RO. Spare the rod and spoil the eye. Br J Ophthalmol 2005; 89(6): 764-769.

6 Ramsey DJ, Arden GB. Hypoxia and dark adaptation in diabetic interactions, consequences, and therapy. Curr Diab Rep 2015; 15(12): 118.

7 Kern TS, Engerman RL. Capillary lesions develop in retina rather than cerebral cortex in diabetes and experimental galactosemia. Arch Ophthalmol 1996; 114: 306-310.

8 de Gooyer TE, Stevenson KA, Humphries P, Simpson DA, Gardiner TA, Stitt AW. Retinopathy is reduced during experimental diabetes in a mouse model of outer retinal degeneration. Invest Ophthalmol Vis Sci 2006; 47 (12): 5561-5568.

9 Ames A, Li YY, Heher EG, Kimble CR. Energy metabolism of rabbit retina as related to function: high cost of $\mathrm{Na}$ transport. J Neurosci 1992; 12: 840-853.

10 Linsenmeier RA, Braun RD. Oxygen distribution and consumption in the cat retina during normoxia and hypoxemia. J Gen Physiol 1992; 99(2): 177-197.

11 Braun RD, Linsenmeier RA, Goldstick TK. Oxygen consumption in the inner and outer retina of the cat. Invest Ophthalmol Vis Sci 1995; 36(3): 542-554.

12 Haugh LM, Linsenmeier RA, Goldstick TK. Mathematical models of the spatial distribution of retinal oxygen tension and consumption, including changes upon illumination. Ann Biomed Eng 1990; 18(1): 19-36.

13 Ahmed J, Braun RD, Dunn Jr R, Linsenmeier RA. Oxygen distribution in the macaque retina. Invest Ophthalmol Vis Sci 1993; 34(3): 516-521.

14 Wangsa-Wirawan ND, Linsenmeier RA Retinal oxygen: fundamental and clinical aspects. Arch Ophthalmol 2003; 121 (4): 547-557.

15 Lau JC, Linsenmeier RA. Oxygen consumption and distribution in the Long-Evans rat retina. Exp Eye Res 2012; 102: 50-58.

16 Wang S, Birol G, Budzynski E, Flynn R, Linsenmeier RA. Metabolic responses to light in monkey photoreceptors. Curr Eye Res 2010; 35(6): 510-518.

17 Birol G, Wang S, Budzynski E, Wangsa-Wirawan ND, Linsenmeier RA. Oxygen distribution and consumption in the macaque retina. Am J Physiol Heart Circ Physiol 2007; 293 (3): H1696-H1704.

18 Okawa H, Sampath AP, Laughlin SB, Fain GL. ATP consumption by mammalian rod photoreceptors in darkness and in light. Curr Biol 2008; 18(24): 1917-1921.

19 Haugh-Scheidt LM, Griff ER, Linsenmeier RA. Light-evoked oxygen responses in the isolated toad retina. Exp Eye Res 1995; 61: 73-81.

20 Muir ER, Rentería RC, Duong TQ. Reduced ocular blood flow as an early indicator of diabetic retinopathy in a mouse model of diabetes. Invest Ophthalmol Vis Sci 2012; 53(10): 6488-6494.

21 Cao J, McLeod S, Merges CA, Lutty GA. Choriocapillaris degeneration and related pathologic changes in human diabetic eyes. Arch Ophthalmol 1998; 116(5): 589-597.

22 Bailey CC, Sparrow JM. Visual symptomatology in patients with sight-threatening diabetic retinopathy. Diabet Med 2001; 18(11): 883-888.
23 Drasdo N, Chiti Z, Owens DR, North RV. Effect of darkness on inner retinal hypoxia in diabetes. Lancet 2002; 359: 2251-2253.

24 Harris A, Arend O, Danis RP, Evans D, Wolf S, Martin BJ. Hyperoxia improves contrast sensitivity in early diabetic retinopathy. Br J Ophthalmol 1996: 80: 209-213.

25 Kurtenbach A, Mayser HM, Jagle H, Fritsche A, Zrenner E. Hyperoxia, hyperglycemia, and photoreceptor sensitivity in normal and diabetic subjects. Vis Neurosci 2006; 23: 651-661.

26 Takamura Y, Tomomatsu T, Matsumura T, Arimura S, Gozawa M, Takihara $Y$ et al. The effect of photocoagulation in ischemic areas to prevent recurrence of diabetic macular edema after intravitreal bevacizumab injection. Invest Ophthalmol Vis Sci 2014; 55 (8): 4741-4746.

27 Nguyen QD, Shah SM, Van Anden E, Jennifer U, Sung JU, Vitale $\mathrm{S}$ et al. Supplemental oxygen improves diabetic macular edema: a pilot study. Invest Ophthalmol Vis Sci 2004; 45: 617-624.

28 West SD, Nicoll DJ, Stradling JR. Prevalence of obstructive sleep apnoe men with type 2 diabetes. Thorax 2006; 61(11): 945-950.

29 Leong WB, Jadhakhan F, Taheri S, Chen YF, Adab P, Thomas GN. Effect of obstructive sleep apnoea on diabetic retinopathy and maculopathy: a systematic review and meta-analysis. Diabet Med 2015; e-pub ahead of print 29 May 2015; doi:10.1111/dme.12817.

30 Nannapaneni S, Ramar K, Surani S. Effect of obstructive sleep apnea on type 2 diabetes mellitus: a comprehensive literature review. World J Diabetes 2013; 4: 238-244.

31 Mason RH, West SD, Kiire CA, Groves DC, Lipinski HJ, Jaycock A et al. High prevalence of sleep disordered breathing in patients with diabetic macular edema. Retina 2012; 32 (9): 1791-1798.

32 Nishimuraa A, Kasai T, Tamura H, Yamato A, Yasuda D, Nagasawa K et al. Relationship between sleep disordered breathing and diabetic retinopathy. Analysis of 136 patients with diabetes. Diabetes Res Clin Pract 2015; 109: 306-311.

33 Arden GB, Gündüz MK, Kurtenbach A, Völker M, Zrenner E, Gündüz SB et al. A preliminary trial to determine whether prevention of dark adaptation affects the course of early diabetic retinopathy. Eye (Lond) 2010; 24(7): 1149-1155.

34 Arden GB, Jyothi S, Hogg CH, Lee YF, Sivaprasad S. Regression of early diabetic macular oedema is associated with prevention of dark adaptation. Eye (Lond) 2011; 25(12): 1546-1554.

35 Sivaprasad S, Arden G, Prevost AT, Crosby-Nwaobi R, Holmes H, Kelly J et al. A multicentre phase III randomised controlled single-masked clinical trial evaluating the clinical efficacy and safety of light-masks at preventing darkadaptation in the treatment of early diabetic macular oedema (CLEOPATRA): study protocol for a randomised controlled trial. Trials 2014; 15: 458.

36 Kern TS, Berkowitz BA. Photoreceptors in diabetic retinopathy. J Diabetes Investig 2015; 6(4): 371-380.

37 Yagi T, MacLeish PR. Ionic conductances of monkey solitary cone inner segments. J Neurophysiol 1994; 71: 656-665.

38 Hoang QV, Linsenmeier RA, Chung CK, Curcio CA. Photoreceptor inner segments in monkey and human retina: mitochondrial density, optics, and regional variation. Vis Neurosci 2002; 19: 395-407.

39 Lucas RJ, Peirson SN, Berson DM, Brown TM, Cooper HM, Czeisler CA et al. Measuring and using light in the melanopsin age. Trends Neurosci 2014; 37(1): 1-9. 